\title{
PENANGGULANGAN MASALAH BANJIR DAN PENGOLAHAN SAMPAH MANDIRI DENGAN METODE TAKAKURA (DESA BERBEK KECAMATAN WARU SIDOARJO)
}

\author{
Safrin Zuraidah ${ }^{1)}$, Bambang Sujatmiko ${ }^{2)}$, Maulidya Octaviani Bustamin ${ }^{3)}$ \\ ${ }^{1,2,3}$ Fakultas Teknik, Universitas Dr. Soetomo \\ email: safrin.zuraidah@unitomo.ac.id
}

\begin{abstract}
Abstrak
Permasalahan sampah menjadi masalah yang memprihatinkan, jika tidak diperhatikan. Beberapa faktor penyebab nya adalah, pertambahan jumlah penduduk, banyaknya makanan instan dengan kemasan plastik, kebiasaan membuang sampah sembarangan, kebiasaan mengkonsumsi makanan instan dalam kemasan, hingga pada kebiasaan membuang sampah tanpa memilah antara sampah organik dan non organik yang tentu akan merusak ekosistem. Permasalahan yang sama juga dialami Kelurahan Berbek Kabupaten Sidoarjo, persoalan sampah dan banjir yang senantiasa dihadapi oleh perkotaan tidak bisa hanya menjadi tanggung jawab pemerintah saja, namun masyarakat selaku salah satu produsen sampah rumah tangga seharusnya senantiasa ikut membantu mengurangi jumlah sampah yang ada. Hal ini perlu memberi pemahaman kepada masyarakat akan kepedulian lingkungan khususnya tentang pengolahan sampah rumah tangga dan pelestarian air untuk masa depan yang berbasis konservasi air. Hasil yang dicapai dari kegiatan ini adalah masyarakat Desa Berbek sadar dan memahami pentingnya lingkungan yang bersih, sudah tidak ada sampah yang berserakan, genangan air atau banjir dapat dikurangi, dan mampu mempraktekkan cara pengelolaan sampah mandiri.
\end{abstract}

Kata Kunci: Sampah, organik, lingkungan, konservasi

\begin{abstract}
Waste has become a problem that is really worrying everywhere. If you pay close attention, there are indeed a number of factors that cause waste problems to become serious. First, population growth. Second, more and more instant food with plastic packaging. Third, the habit of littering, the habit of consuming instant food in packaging, to the habit of throwing garbage without sorting between organic and non-organic waste will damage the ecosystem. The same problem is also experienced by Berbek Village in Sidoarjo Regency, the problem of waste and flooding that is always faced by the city cannot only be the responsibility of the government, but the community as one of the producers of household waste should always help reduce the amount of waste. This needs to provide an understanding to the community of environmental concerns, especially regarding household waste management and water conservation for the future based on water conservation. The results achieved from this activity are that the village community is aware of and understands the importance of a clean environment, there is no garbage scattered, puddles or floods can be reduced, and are able to practice independent waste management methods.
\end{abstract}

Keywords: Garbage, organic, environment, conservation

\section{PENDAHULUAN}

Sampah.entah karena apa, belakangan masalah sampah menjadi masalah yang benar-benar memperihatinkan khususnya di Indonesia.
Jika diperhatikan baik-baik memang beberapa faktor menjadi penyebab masalah sampah menjadi serius.Pertama, Pertambahan jumlah penduduk, kedua, semakin banyaknya makanan instan dengan kemasan plastik, ketiga, Kebiasaan manusia 
yang semakin kesini semakin merugikan lingkungan.

Seiring dengan bertambahnya waktu Desa Berbek mengalami perubahan fungsi lahan menjadi daerah pemukiman padat penduduk.persoalan yang multikompleks akibat urbanisasi menyebabkan lahan bagian dari Kota Sidoarjo yang merupakan penyangga Kota Surabaya hampir ditutupi oleh bangunan dan daerah kedap air, karena tertutup semen. Lahan-lahan yang semula menjadi penampungan air, kini diurug menjadi perumahan.

Sehingga, air tidak terserap, tetapi meluber dan menggenangi permukiman penduduk. Disamping itu kesadaran dan pengetahuan masyarakat terhadap lingkungan relative kurang peka, setiap menghadapi permasalahan mengenai lingkungan diselesaikan dengan mengambil jalan pintas tanpa memikirkan dampak yang terjadi untuk jangka panjang.

\section{METODE PELAKSANAAN}

1. Analisa kebutuhan

a. Tahapan awal ini berupa analisis kebutuhan meliputi kebutuhan output, proses dan Hasil Analisa kebutuhan, dipresentasikan kepada kelompok masyarakat, untuk mendapatkan masukan yang sesuai dengan kebutuhan.

b. Tim membuat solusi alternative yang sesuai dengan kebutuhan dan sumber daya yang tersedia, agar solusi yang ditawarkan dapat dijalankan oleh pihak LKM Berbek Mandiri dan tim menyepakati solusi yang dipilih untuk diterapkan.

2. Desain dan Pembuatan Produk

Proses desain meliputi proses pembuatan kompos mandiri dengan menawarkan metode keranjang Takakura. Hasil perancangan berupa metode yang akan dipresentasikan dan dikonsultasikan ke wakil masyarakat yang ditunjuk oleh LKM untuk memverifikasi kesesuaian desain dengan kebutuhan warga.
3. Penyuluhan dan pelatihan

Dari hasil verifikasi dengan warga maka diputuskan pengolahan sampah mandiri dengan metode Takakura yang tindak lanjutnya dengan mengumpulkan warga untuk mengadakan pelatihan pembuatan kompos organik dan penyuluhan penanggulangan banjir pada musim hujan

4. Implementasi

Produk yang telah dibuat diimplmentasikan ke warga desa Berbek dengan terlebih dahulu memberikan pelatihan pengelolaan dan pembuatan pupuk kompos.

\section{HASIL DAN PEMBAHASAN}

Pemahaman yang salah tentang pengertian "renewable resources", yakni, meskipun air tanah adalah renewable resources, tetapi pembaharuannya memerlukan proses yang panjang dan waktu yg lama, puluhan hingga ratusan tahun. (M. Bisri, 2009).

Oleh karena itu, bekerjasama dengan aparat desa, Lembaga Keswadayaan Masyarakat (LKM), KOTAKU, dan Kepada Desa Berbek masyarakat mendapatkan wawasan terhadap lingkungan di sekitarnya seperti pembangunan yang berwawasan lingkungan. Misalnya, konservasi air dengan menabung air hujan, dengan cara menghindari halaman ditutup dengan plesteran, dan tetap memakai paving.

Mengelola siklus hidrologi secara keseluruhan, Yang dikelola bukan hanya debit banjir rencana saja tetapi seluruh debit sungai, baik pada saat kemarau maupun saat banjir. Integrasi pengelolaan lahan dan air. Banjir adalah produk DAS (Debit Air Sungai) dengan segala isi dan kegiatannya. (Surjono, 2009)

Pengendalian banjir bukan hanya mengurangi banjirnya tapi juga mengurangi kerugian/korbannya. Korban dalam hal ini bukan dilihat sebagai 
masalah tapi harus dilihat sebagai bagian dari solusi. (Slamet B. S., 2009). Korban perlu diberi pemahaman yang benar dan menyesuaikan diri dengan karakter banjir setempat.

Air dari talang atap masuk ke bak kontrol tidak dibuat kedap, tapi dipasang papa paralon yg dilubangi pd kedalaman $1 \mathrm{~m}$, sehingga air hujan yang bersih meresap ke dalam tanah (inflitrasi), dan melarang sampah dibakar tapi diolah menjadi kompos untuk sampah organik.

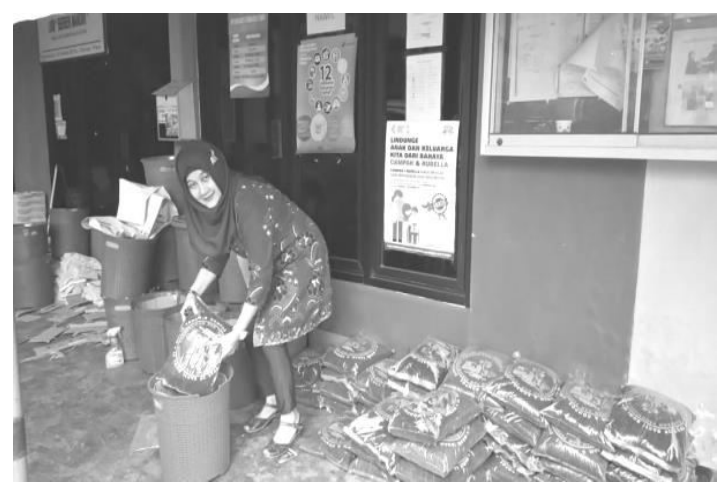

Gambar 1. Alat dan Bahan Keranjang Takakura

Sampah organik diolah dengan menggunakan Metode Takakura untuk dapat dijadikan sebagai pupuk yang bermanfaat bagi lingkungan.

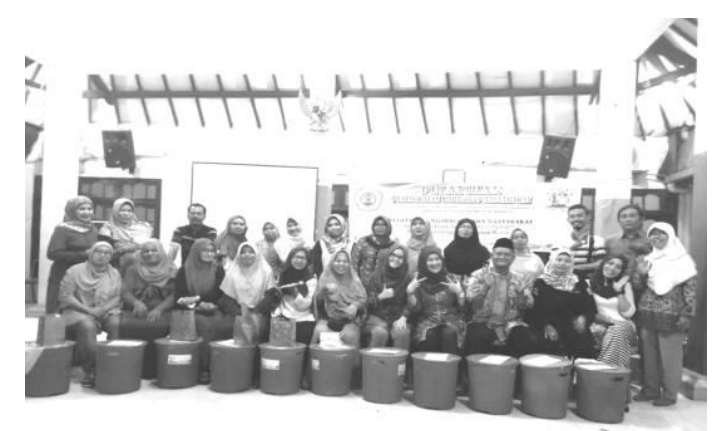

Gambar 2. Pembagian keranjang Takakura kepada Warga

Ketika kita berbuat yang sedikit hanya dengan cara menangani sampah organic di rumah tangga masing-masing, berarti kita sudah membantu melestarikan bumi, efek baiknya begitu banyak, jelas kita sudah ikut berpartisipasi dalam mengurangi menumpuknya sampah, mengurangi populasi lalat dan mencegah berbagai penyakit yang ditimbulkan oleh sampah, kompos hasil sendiri inilah yang merupakan solusi untuk penghijauan dan membantu mengurangi global warming. (N. S. Moerni, 2013)

Diakhir acara, 30 keranjang Takakura dibagikan kepada warga yang hadir.Warga sangat antusias dengan kegiatan ini.Kepala Desa berharap ada keberlanjutandengan topik yang lain, sehingga dapat bermanfaat untuk masyarakat sekitar.

\section{KESIMPULAN}

Pengabdian pada Masyarakat terkait penanggulangan banjir dan pengolahan sampah mandiri dengan Metode Takakura di Desa Berbek Kecamatan Waru Sidoarjo berjalan dengan baik. Hasil yang diperoleh dari pelaksanaan ini adalah masyarakat Desa Berbek dapat mengaplikasikan Metode Takakura sebagai pemanfaatan sampah rumah tangga. Sampah organik yang ada dalam dapur rumah tangga dimanfaatkan menggunakan keranjang Takakura untuk membuat kompos. Kegiatan ini diikuti oleh 40 orang perwakilan RT dan RW.

\section{REFERENSI}

Bambang Subyandono "Pengelolaan Sumber Daya Air Terpadu", Materi Pelatihan tenaga Ahli Konstruksi SDA, Departemen Pekerjaan Umum, 2008

Muhamad Bisri "Teknologi Konservasi Sumber Daya Air" Materi Pelatihan tenaga Ahli Konstruksi SDA, Departemen Pekerjaan Umum, 2008

Mohammad Bisri, 2009, "Permasalahan dalam Pengelolaan Wilayah Sungai", 2009

M Bisri, Donny H, “ Pendayagunaan Sumber Daya Air", materi pelatihan Tenaga Ahli Konstruksi, Dep PU, 2009

Ngesti S. Moerni, "Membuat Kompos Skala Rumah Tangga: Mudah", Kompasiana, 2013 
VOL. 03. NO. 1, JANUARI 2019

Surjono, "Kebijakan dan Aspek-Aspek

Perencanaan Wilayah Kota", Universitas

Brawijaya, 2009

Slamet Budi S, "Pengelolaan Banjir",

Departemen PU, 2009 